\title{
BMJ open Comparing media and family predictors of alcohol use: a cohort study of US adolescents
}

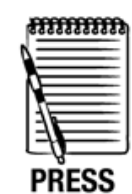

RELEASE

\author{
Mike Stoolmiller, ${ }^{1}$ Thomas A Wills, ${ }^{2}$ Auden C McClure, ${ }^{3,4}$ Susanne E Tanski, ${ }^{3,4}$ \\ Keilah A Worth, ${ }^{5}$ Meg Gerrard, ${ }^{4,6}$ James D Sargent ${ }^{3,4}$
}

To cite: Stoolmiller M, Wills $\mathrm{TA}$, McClure $\mathrm{AC}$, et al. Comparing media and family predictors of alcohol use: a cohort study of US adolescents. BMJ Open 2012;2:e000543. doi:10. 1136/bmjopen-2011-000543

- Prepublication history and additional appendix for this paper are available online. To view these files please visit the journal online (http://dx. doi.org/10.1136/ bmjopen-2011-000543)

Received 18 November 2011 Accepted 15 December 2011

This final article is available for use under the terms of the Creative Commons Attribution Non-Commercial 2.0 Licence; see http://bmjopen.bmj.com

\footnotetext{
${ }^{1}$ College of Education, University of Oregon, Eugene, Oregon, USA ${ }^{2}$ Prevention and Control Program, University of Hawaii Cancer Center, Honolulu, Hawaii, USA ${ }^{3}$ Department of Pediatrics, Dartmouth Medical School, Hanover, New Hampshire, USA

${ }^{4}$ Cancer Control Research Program, Norris Cotton Cancer Center, Lebanon, New Hampshire, USA

${ }^{5}$ Department of Psychology, St Catherine University, Saint Paul, Minnesota, USA

${ }^{6}$ Department of Psychiatry, Dartmouth Medical School, Hanover, New Hampshire, USA
}

Correspondence to Dr James D Sargent; james. d.sargent@dartmouth.edu

\section{ABSTRACT}

Objective: To compare media/marketing exposures and family factors in predicting adolescent alcohol use. Design: Cohort study.

Setting: Confidential telephone survey of adolescents in their homes.

Participants: Representative sample of 6522 US adolescents, aged 10-14 years at baseline and surveyed four times over 2 years.

Primary outcome measure: Time to alcohol onset and progression to binge drinking were assessed with two survival models. Predictors were movie alcohol exposure (MAE), ownership of alcohol-branded merchandise and characteristics of the family (parental alcohol use, home availability of alcohol and parenting). Covariates included sociodemographics, peer drinking and personality factors.

Results: Over the study period, the prevalence of adolescent ever use and binge drinking increased from $11 \%$ to $25 \%$ and from $4 \%$ to $13 \%$, respectively. At baseline, the median estimated MAE from a population of 532 movies was $4.5 \mathrm{~h}$ and $11 \%$ owned alcoholbranded merchandise at time 2. Parental alcohol use (greater than or equal to weekly) was reported by $23 \%$ and $29 \%$ of adolescents could obtain alcohol from home. Peer drinking, MAE, alcohol-branded merchandise, age and rebelliousness were associated with both alcohol onset and progression to binge drinking. The adjusted hazard ratios for alcohol onset and binge drinking transition for high versus low MAE exposure were $2.13(95 \% \mathrm{Cl} 1.76$ to 2.57$)$ and 1.63 (1.20 to 2.21), respectively, and MAE accounted for $28 \%$ and $20 \%$ of these transitions, respectively. Characteristics of the family were associated with alcohol onset but not with progression.

Conclusion: The results suggest that family focused interventions would have a larger impact on alcohol onset while limiting media and marketing exposure could help prevent both onset and progression.

\section{INTRODUCTION}

Underage drinking is prevalent ${ }^{12}$ and represents an important risk factor for risky sexual behaviour, ${ }^{3}{ }^{4}$ injury and mortality during adolescence $^{56}$ and subsequent alcohol abuse and dependence. ${ }^{7} 8$ Alcohol use or brands

\section{ARTICLE SUMMARY}

Article focus

- Predictors of drinking during adolescence.

- Particular focus on predicting onset versus binge drinking and media/marketing exposures versus family risk factors.

Key messages

- Somewhat different risk factors exist for alcohol onset versus binge drinking.

- Movie alcohol, alcohol marketing, friend drinking and sensation seeking predicted both outcomes.

- Parent drinking, availability of alcohol at home and parenting predicted alcohol onset, not binge drinking.

Strengths and limitations

- Strengths include longitudinal design, large sample size and analysis that accounted for attrition.

- Limitations include inability to generalise beyond US adolescents or beyond this age bracket.

are depicted in $80 \%-95 \%$ of movies, and drinking is mostly portrayed positively. ${ }^{9-13}$ Previous research on youth in regional samples of US ${ }^{12}$ and German adolescents ${ }^{14} 15$ has demonstrated an association between viewing alcohol use in movies and early onset of drinking. In the German study, $80 \%$ of exposure came from internationally distributed Hollywood movies, so decisions made by US production companies on how alcohol is depicted may impact drinking world wide. Alcohol marketing activities, such as branded merchandise distribution, ${ }^{16}$ have also been linked to teen drinking. ${ }^{17}$

This study tests the hypothesis that exposure to movie alcohol use and alcohol-branded merchandise predicts teen alcohol onset and progression to binge drinking. Prior research suggests that predictors of substance use onset may be different from predictors of its progression, ${ }^{18}{ }^{19}$ but this has not been tested for media/marketing exposures. Previously, using data from this longitudinal sample of 
US adolescents, we found that the association between movie alcohol exposure (MAE) and drinking frequency was mediated through drinking cognitions ${ }^{20}$ and that an association between MAE and alcohol problems was mediated, in part, through quantity of alcohol consumed. ${ }^{21}$ We have also noted that Black adolescents and those $\mathrm{e}^{22}$ high in sensation seeking were less responsive to media influence. The present study addresses several issues not addressed in prior research. We test the hypothesis about prediction of onset and progression, and for each transition, we compare the effect of movie/ marketing exposure with the effects of family and peer predictors that have been linked with alcohol use by others. ${ }^{23}{ }^{24}$ Moreover, this research addresses the public health importance of mass media by determining the proportions of the drinking transitions that may be attributed to MAE.

\section{METHODS}

\section{Participants and procedure}

Between June and October, 2003, we conducted a random digit dial telephone survey of 6522 US adolescents aged 10-14 years. The telephone surveys were conducted by trained interviewers using a computer-assisted telephone interview system from Westat (Rockville, Maryland, USA), a national research organisation with survey sites across the US. Interviewers were trained to administer the survey in English or Spanish. We obtained parental consent and adolescent assent prior to interviewing each respondent. To protect confidentiality, adolescents indicated their answers to sensitive questions by pressing numbers on the telephone, rather than speaking aloud. All aspects of the survey were approved by the institutional review boards at Dartmouth Medical School and Westat.

Selection of the sample (online appendix figure 1) involved three stages, through which we identified a listassisted randomly generated sample of 377850 residential phone numbers (stage 1), identified households with age-eligible children (stage 2) and enrolled age-eligible adolescents into the study (stage 3 ). In stage 1 , we used an automated system in combination with interviewer calls to purge non-working and business numbers from the list, which reduced the sample to 129002 known residential telephone numbers. In stage 2, interviewers called each number and successfully completed screener interviews with 69516 households. Through the screening interviews, we identified 9849 eligible households with adolescents between 10 and 14 years of age. For households with more than one ageeligible adolescent, we randomly selected one for enrolment. In stage 3, we obtained permission from $77 \%$ $(\mathrm{N}=7492)$ of the parents to interview their child, and $87 \%(\mathrm{~N}=6522)$ of eligible adolescents agreed to participate and completed the survey.

The American Association for Public Opinion Research identifies several ways to calculate survey response. $^{25}$ The completion rate (the number of completed interviews $(\mathrm{N}=6522)$ divided by the number of eligible households $(\mathrm{N}=9849)$ ) for this survey was $66 \%$. The response rate is more conservative and includes estimates of eligible households lost during stages 1 and 2 (see online appendix figure 1) ${ }^{25}$ Using methods of Brick et al, ${ }^{26}$ we estimated that 15057 of the 38696 non-answered phone numbers in stage 1 were residential. In addition, 59667 households did not complete the screening interview in stage 2. Assuming that the same proportion of these $74724(15057+$ $59667)$ unscreened households had age-eligible adolescents as in the screened sample $(0.14)$, we estimate that 10587 households in stages 1 and 2 could have been eligible for the study. When these households are included in the denominator, our most conservative estimate of the response rate is 32\% (6522 interviewed adolescents/an estimated $20436(9849+10587)$ eligible households). Online appendix figure 2 illustrates the geographic coverage of the sampling procedure, which captured adolescents from all 50 US states and which reflects the geographic distribution of the US population. As an additional test of sample representativeness, we assessed the distributions of age, sex, household income and census region in the unweighted sample and found that they were almost identical to percentages approximated in the 2000 US Census (online appendix table 1). Compared with the 2000 US Census, the unweighted sample had a higher percentage of Hispanics and a slightly lower percentage of African-Americans.

The study was originally funded to study smoking and was therefore powered to detect an association between movie smoking and smoking onset. For that outcome, we determined that we needed to successfully follow-up 2200 baseline never-smokers in order to achieve a power of $90 \%$ to detect an adjusted OR of 1.4 using a two-sided test with $\alpha=0.05$.

There were few missing data for items on the baseline questionnaire; for example, at baseline, 6520 of 6522 participants answered the question about ever binge drinking. After the baseline questionnaire, the adolescents were followed up every 8 months for three more telephone surveys $(n=5503,5019$ and 4575 for waves 2, 3 and 4, respectively). Attrition analyses indicated that adolescents lost to follow-up were more likely to be nonCaucasian; were from families with lower parental education and income, rented versus owned their residence; had poorer school performance and had higher levels of sensation seeking. Baseline drinking status (ever vs never tried alcohol) did not predict attrition, but to account for attrition bias related to other variables, estimation was carried out after multiple imputation using the standard missing at random assumption (ie, missing data are assumed missing at random conditional on observed predictors included in the model). ${ }^{27}$ The imputation model included all the predictors in the alcohol models plus a number of auxiliary variables that were not of direct theoretical interest but were nonetheless predictive of missingness so as to improve 
the quality of the imputations and make the missing at random assumption more plausible. ${ }^{28}$

\section{Movie alcohol exposure measurement}

Exposure to movie alcohol use was assessed using the previously validated Beach method. ${ }^{29}$ The top 100 US box office hits for each of the 5 years preceding the baseline survey $(1998-2002, \mathrm{~N}=500)$ and 32 movies earning $>\$ 15$ million in gross US box office revenues during the first quarter of 2003 were selected. Each adolescent survey included 50 movies randomly selected from the larger sample of 532, stratified by the Motion Picture Association of America rating, so that the distribution of movies in each list reflected the distribution in the full sample of movies $(19 \% \mathrm{G} / \mathrm{PG}, 41 \%$ PG-13 and 40\% R). Respondents were asked (Yes/No) whether they had ever seen each movie title on their individual list. We have previously shown that adolescents correctly remember movies they have seen with high reliability. ${ }^{29}$

The movies were content analysed by trained coders who timed the number of seconds of on-screen alcohol use (mean $\kappa$ for coding reliability on a $10 \%$ subsample of movies was 0.86). Alcohol use was defined as a character's actual or implied consumption or the purchase of alcohol. The measure of MAE was based on the summed total of timed alcohol use in the films that each adolescent had seen.

\section{Ownership of alcohol-branded merchandise}

Ownership of branded merchandise is a key item in the measurement of receptivity to marketing as developed by Pierce and colleagues for tobacco marketing. ${ }^{30}$ This risk factor was not measured at baseline but was included at T2, T3 and T4 surveys. Thus, the hazard estimates are determined over two and not three periods as was the case for the other variables. It was assessed through the question, 'Do you own something with the name of a beer, wine, or liquor brand on it, like a t-shirt or a hat?'

\section{Other predictor variables}

The analyses also included age, race/ethnicity (three binary variables for Black, Hispanic and other ethnicity, coded with Whites as the reference group), gender, household income and parental education, mediaviewing habits-hours watching television on a school day and how often the participant viewed movies together with his/her parents-and receptivity to alcohol marketing (based on whether or not the adolescent owned alcohol-branded merchandise at waves 2-4). ${ }^{31}$ Family predictors included perceived inhome availability of alcohol, subject-reported parental alcohol use (assessed at the $16 \mathrm{M}$ survey and assumed to be invariant) and perceptions of authoritative parenting $(\alpha=0.80) .{ }^{32}$ Other covariates included school performance, extracurricular participation, number of friends who used alcohol, weekly spending money, sensation seeking (4-wave Cronbach's $\alpha$ range $=0.57-0.62)^{33}$ and rebelliousness $(0.71-0.76) .{ }^{34}$ All survey items are listed in table S1.

\section{Adolescent alcohol use}

Alcohol use onset was assessed at each wave by the question: "Have you ever drunk alcohol that your parents did not know about? By alcohol we mean beer, wine, wine coolers or liquor, like whisky, vodka, or gin" (Yes/No), defined in this way to exclude parentally sanctioned sips of alcohol. Binge drinking was assessed by asking "Have you ever had 5 or more drinks of alcohol in a row, that is, within a couple of hours?" (ever-binge drinker) and "Did you have 5 or more drinks of alcohol in a row during the past month?" (30-day binge drinker). To ensure confidentiality in these home-based surveys, subjects indicated responses by pressing numbers on the telephone.

\section{Statistical analysis}

From the three drinking outcomes, we estimated the relation between baseline assessment of MAE and covariates with time to event for two survival models: an alcohol onset model for the transition from neverdrinker $\rightarrow$ ever-drinker or ever-binge drinker and a progression-to-binge-drinking model for ever-drinker $\rightarrow$ ever-binge drinker and ever-binge drinker $\rightarrow$ 30-day binge drinker. We tested for within-subject correlation between the two transition processes and found none, that is, time to onset was not associated with time to progression, net of covariates. The MICE procedure in the R statistical software package ${ }^{35}$ was used to stochastically impute missing data. ${ }^{36}$ For descriptive statistics, we averaged across the 20 imputations to obtain a best estimate for each missing data point.

Discrete time hazard survival models ${ }^{37}$ were fit to each of the 20 imputed complete data sets using a complementary $\log$-log regression routine in $\mathrm{R}$ and following standard procedures for pooling the estimates and obtaining SEs. ${ }^{36}$ All predictors were entered in the model simultaneously. The measure of the association is the adjusted hazard ratio (AHR), which assesses time to onset of the outcome and may be interpreted like a relative risk. To aid in comparison of the AHRs, continuous covariates were scaled such that 0 corresponded to the 5th percentile and 1 to the 95th percentile for their distributions, with extreme values in either direction recoded to 0 or 1 to minimise outlier influence. Ordinal variables were scaled so that the lowest value was equal to 0 and the highest value was equal to 1 . Continuous and ordinal variables that were protective (eg, authoritative parenting, family income) were reversed (to unskilled parenting, low family income involvement), so that all HRs were $\geq 1.0$. This rescaling procedure allowed for comparison of the effect sizes between continuous, dichotomous and ordered categorical variables. For all models, results for main effects were judged significant if $\mathrm{p}<0.05$.

Attributable fraction calculations (adjusted for covariate effects) were carried out after model fitting by 
Table 1 Description of the sample at baseline

\begin{tabular}{|c|c|}
\hline Variable & N (\%) \\
\hline \multicolumn{2}{|l|}{ Sociodemographics } \\
\hline \multicolumn{2}{|l|}{ Age } \\
\hline 10 years & $1186(18)$ \\
\hline 11 years & $1303(20)$ \\
\hline 12 years & $1338(21)$ \\
\hline 13 years & $1418(22)$ \\
\hline 14 years & $1277(20)$ \\
\hline \multicolumn{2}{|l|}{ Race/ethnicity } \\
\hline Caucasian & $4037(62)$ \\
\hline African-American & $704(11)$ \\
\hline Hispanic & $1222(19)$ \\
\hline Other & $559(9)$ \\
\hline \multicolumn{2}{|l|}{ Sex } \\
\hline Male & $3350(51)$ \\
\hline Female & $3172(49)$ \\
\hline \multicolumn{2}{|l|}{ Family income $(\times 1000)$} \\
\hline$<\$ 20$ & $475(7)$ \\
\hline$\$ 20-\$ 29$ & $722(11)$ \\
\hline$\$ 30-\$ 49$ & 804 (12) \\
\hline$\$ 50-\$ 74$ & $1360(21)$ \\
\hline$\$ 75-\$ 99$ & $1296(20)$ \\
\hline$\geq \$ 100$ & $1865(29)$ \\
\hline \multicolumn{2}{|l|}{ Parent education } \\
\hline$\leq 9$ th grade & $402(6)$ \\
\hline 9 th -11 th grade & $478(7)$ \\
\hline 12th grade & $260(4)$ \\
\hline HS diploma & $1481(23)$ \\
\hline Voc/Tech & $234(4)$ \\
\hline Some college & $1127(17)$ \\
\hline Associate degree & $550(8)$ \\
\hline Bachelor's degree & $1197(18)$ \\
\hline Postgraduate education & 793 (12) \\
\hline \multicolumn{2}{|l|}{ Family and friends } \\
\hline \multicolumn{2}{|l|}{ Parent alcohol use* } \\
\hline Never & $1270(19)$ \\
\hline Once per year & $1913(29)$ \\
\hline Once per month & $1872(29)$ \\
\hline Once per week & $1103(17)$ \\
\hline Daily use & $364(6)$ \\
\hline
\end{tabular}

Home availability of alcohol (could you get alcohol from home without your parents knowing?)

Definitely no

Probably no

Probably yes

Definitely yes

Peer alcohol use

None

Some

Most

Media and marketing

Television viewing

None

$<1 \mathrm{~h} /$ day

$1-2$ h/day

3-4 h/day

$>4$ h/day

\begin{tabular}{|c|c|c|}
\hline Variable & & N (\%) \\
\hline \multicolumn{3}{|c|}{$\begin{array}{l}\text { Movie viewing with parents (How often do you watch } \\
\text { movies with parents?) }\end{array}$} \\
\hline Most of the time & & $152(2)$ \\
\hline Sometimes & & $1705(26)$ \\
\hline Once in a while & & $2448(38)$ \\
\hline Never & & $2217(34)$ \\
\hline \multicolumn{3}{|c|}{$\begin{array}{l}\text { Receptive to alcohol marketing (owns alcohol-branded } \\
\text { merchandise) } \dagger\end{array}$} \\
\hline No & & $4895(89)$ \\
\hline Yes & & $597(11)$ \\
\hline \multicolumn{3}{|l|}{ Adolescent characteristics } \\
\hline \multicolumn{3}{|l|}{ School performance } \\
\hline Below average & & $181(3)$ \\
\hline Average & & $1625(25)$ \\
\hline Above average & & 2734 (42) \\
\hline Excellent & & $1982(30)$ \\
\hline \multicolumn{3}{|l|}{ Weekly spending money } \\
\hline None & & $937(14)$ \\
\hline$\$ 1-\$ 5$ & & 764 (12) \\
\hline$\$ 6-\$ 10$ & & $1551(24)$ \\
\hline$\$ 11-\$ 15$ & & $1652(25)$ \\
\hline$\$ 16-\$ 20$ & & 920 (14) \\
\hline$\$ 21-\$ 50$ & & $568(9)$ \\
\hline$\$ 50+$ & & $130(2)$ \\
\hline Continuous variables & Median & IQR \\
\hline Authoritative parenting & 2.4 & $2.1-2.7$ \\
\hline Movie alcohol exposure (h) & 4.5 & $2.2-8.0$ \\
\hline Sensation seeking & 1 & $0.5-1.5$ \\
\hline Rebelliousness & 0.5 & $0.3-0.8$ \\
\hline Extracurricular involvement & 1.8 & $1.5-2.2$ \\
\hline
\end{tabular}

${ }^{*}$ Assessed at 16 months, imputed for baseline numbers, time invariant.

†Assessed at 8 months, used as predictor from 8 months on.

obtaining the model-predicted number of events with the observed data and the model-predicted number of events when levels of MAE in our sample were altered along two scenarios. For the first scenario, the intervention' scenario, we lowered all scores for MAE by $25 \%$ to model the results of an intervention that successfully reduced MAE exposure. For the second scenario, the 'full effect' scenario, we lowered all scores for MAE to the 5th percentile level to indicate what might happen if alcohol was completely removed from all movies the adolescents had watched. For each of the 20 imputations, we obtained estimates and SEs for the attributable fractions using 100 bootstrap replications. The bootstrap estimates and SEs were then pooled across the 20 multiple imputation models.
$360(6)$

$1261(19)$

3041 (47)

$1323(20)$

537 (8)
Continued

\section{RESULTS}

Description of the cohort

Table 1 describes the predictor variables at baseline. Age and gender were equally represented. Race/ethnicity and other demographic variables were broadly reflective of the US population, with $11 \%$ Black and $19 \%$ Hispanic ethnicity. Some $18 \%$ of families were low income, with 
Table 2 Alcohol use and binge drinking in the cohort

\begin{tabular}{|c|c|c|c|c|}
\hline Survey & Tried drinking (\%) & $\begin{array}{l}\text { Drinking ou } \\
\text { Ever binge }\end{array}$ & Isition (\%) & 30-day binge drink (\%) \\
\hline \multicolumn{5}{|l|}{ Prevalence } \\
\hline Baseline & 11 & 4 & & 1 \\
\hline 8 months & 16 & 6 & & 2 \\
\hline 16 months & 20 & 10 & & 4 \\
\hline 24 months & 25 & 13 & & 6 \\
\hline Incidence & $\begin{array}{l}\text { Never } \\
\rightarrow \text { tried }\end{array}$ & $\begin{array}{l}\text { Never } \\
\rightarrow \text { ever binge }\end{array}$ & $\begin{array}{l}\text { Tried } \\
\rightarrow \text { ever binge }\end{array}$ & $\begin{array}{l}\text { Ever binge } \\
\rightarrow 30 \text {-day binge }\end{array}$ \\
\hline $\mathrm{B} \rightarrow 8$ months & 8 & 3 & 24 & 29 \\
\hline $8 \rightarrow 16$ months & 6 & 2 & 22 & 25 \\
\hline $16 \rightarrow 24$ months & 7 & 3 & 15 & 23 \\
\hline
\end{tabular}

$7 \%$ having incomes of $\$ 20000$ or less and $11 \%$ having income between $\$ 20000$ and $\$ 29000 /$ year. At baseline, the median estimated MAE from the pool of 532 movies was $4.5 \mathrm{~h}$, and at $\mathrm{T} 2,11 \%$ of the respondents reported owning alcohol-branded merchandise. Friend alcohol use was reported by $23 \%$, parental alcohol use (greater than or equal to weekly) by $23 \%$ and could obtain alcohol from home by $29 \%$ of respondents.

Alcohol use in the cohort

Over the course of the study, the prevalence of tried drinking increased from $11 \%$ to $25 \%$ (table 2). The incidence categories show data for transitions. Among never-drinkers for each 8-month observation period,
$6 \%-8 \%$ transitioned to ever drinking and $2 \%-3 \%$ transitioned to binge drinking. The risk of a transition escalated for ever-drinkers, among whom 15\%-24\% transitioned to binge drinking and 23\%-29\% transitioned to 30-day binge drinking over each 8-month period.

\section{Hazard model: time to onset of drinking}

Crude and AHRs for time to drinking onset are reported in table 3 and compared in figure 1, where they are sorted by magnitude, with all variables scaled so the AHR $>1$. Four variables had AHRs >2.0: peer alcohol use, $\mathrm{AHR}=2.88$ (95\% CI 2.35 to 3.53$)$, age (2.24 (1.81 to 2.77)), MAE (2.13 (1.76 to 2.57)) and sensation seeking

Table 3 Crude and adjusted hazard ratios for time to onset of alcohol use

\begin{tabular}{|c|c|c|}
\hline \multirow[b]{2}{*}{ Predictor variable } & \multicolumn{2}{|l|}{ HR initiation } \\
\hline & Crude & Adjusted \\
\hline \multicolumn{3}{|l|}{ Sociodemographics } \\
\hline Oldest versus youngest & 5.35 (4.49 to 6.37$)$ & $2.24(1.81$ to 2.77$)$ \\
\hline African-American versus Caucasian & 1.05 (0.87 to 1.27$)$ & $0.99(0.80$ to 1.23$)$ \\
\hline Hispanic versus Caucasian & 1.04 (0.91 to 1.19$)$ & $0.98(0.84$ to 1.14$)$ \\
\hline Other non-Caucasian versus Caucasian & $0.87(0.71$ to 1.08$)$ & $0.84(0.68$ to 1.05$)$ \\
\hline Female & 1.01 (0.91 to 1.12$)$ & $1.10(0.99$ to 1.23$)$ \\
\hline High parent education & $0.84(0.71$ to 1.27$)$ & $1.03(0.81$ to 1.29$)$ \\
\hline Low family income & 1.10 (0.93 to 1.30$)$ & $1.09(0.87$ to 1.38$)$ \\
\hline \multicolumn{3}{|l|}{ Family and friends } \\
\hline Parent alcohol use & 2.12 (1.78 to 2.52$)$ & $1.43(1.17$ to 1.75$)$ \\
\hline Alcohol available at home & 3.47 (2.96 to 4.06$)$ & $1.45(1.21$ to 1.74$)$ \\
\hline Unskilled parenting & 5.56 (4.55 to 6.67$)$ & $1.76(1.41$ to 2.20$)$ \\
\hline High peer alcohol use & 8.69 (7.34 to 10.3$)$ & 2.88 (2.35 to 3.53$)$ \\
\hline \multicolumn{3}{|l|}{ Media and marketing } \\
\hline Low TV viewing & $0.67(0.53$ to 0.84$)$ & $1.11(0.87$ to 1.42$)$ \\
\hline High movie alcohol exposure & 5.50 (4.62 to 6.55$)$ & $2.13(1.76$ to 2.57$)$ \\
\hline Views movies without parents & 2.04 (1.67 to 2.50$)$ & $1.22(0.99$ to 1.50$)$ \\
\hline Receptive to alcohol marketing & $2.63(2.19$ to 3.15$)$ & $1.44(1.19$ to 1.74$)$ \\
\hline \multicolumn{3}{|l|}{ Characteristics of adolescent } \\
\hline High sensation seeking & 5.97 (4.98 to 7.15$)$ & $2.08(1.67$ to 2.59$)$ \\
\hline High rebelliousness & 4.08 (3.43 to 4.86$)$ & $1.55(1.25$ to 1.92$)$ \\
\hline Poor school performance & $2.86(2.33$ to 3.45$)$ & $1.32(1.05$ to 1.65$)$ \\
\hline Low extracurricular involvement & 1.6 (1.38 to 2.03$)$ & $1.11(0.91$ to 1.37$)$ \\
\hline High spending money & 3.97 (2.98 to 5.29$)$ & $1.46(1.11$ to 1.92$)$ \\
\hline
\end{tabular}




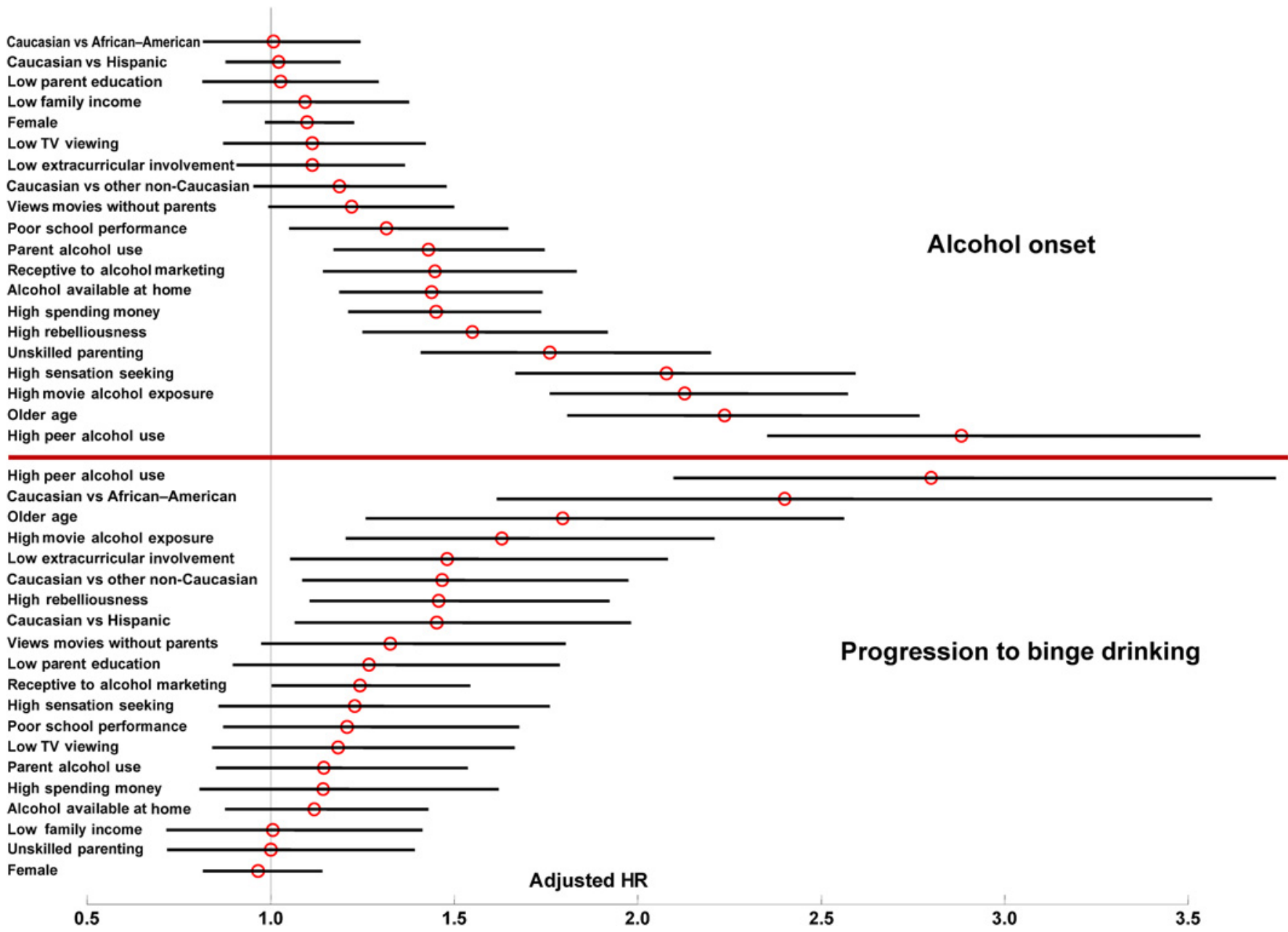

Figure 1 Adjusted hazard ratios (AHRs) for time to alcohol onset among alcohol never users (top panel) and for progression to binge drinking among alcohol experimenters (bottom panel). Each panel sorts the AHRs by size, allowing comparison of media, family, and other risk factors. Error bars represent 95\% confidence intervals. Race/ethnicity dummy contrasts from Tables 3 and 4 were reverse-scaled to represent excess risk of being Caucasian compared to other race/ethnicity groups so that all AHRs are $>1$ to facilitate comparison with other continuous and ordinal risk factors.

(2.08 (1.67 to 2.59$))$. Other variables with statistically significant AHRs included parenting, rebelliousness, weekly spending money, alcohol availability at home, receptivity to alcohol marketing, parent alcohol use and school performance.

The attributable fraction modelling estimated the proportion of drinking onset transitions prevented if MAE were reduced. An intervention that reduced MAE by $25 \%$ across the population would decrease drinking onset by $8 \%$ (adjusted attributable fraction $(\mathrm{AAF})=-0.08 \quad(-0.09,-0.07)) . \quad$ Eliminating $\mathrm{MAE}$ entirely would decrease drinking onset by $28 \%$ $(\mathrm{AAF}=-0.28(-0.30,-0.25))$.

Hazard model: time to progression to binge drinking Results for the multivariate hazard model for transitions to binge drinking among ever-drinkers are illustrated in figure 1, with numeric values for HRs shown in table 4 . High peer alcohol use had an AHR $>2$ (2.80 (2.10, $3.74)$ ) as did White race (vs Black) $(2.40(1.62,3.56)$ ). Variables significantly associated with progression included race and ethnicity (higher AHR for Caucasians vs Hispanic or other non-Caucasians), age, MAE (1.63 $(1.20,2.21))$, extracurricular involvement, rebelliousness and receptivity to alcohol marketing. An intervention that reduced MAE by $25 \%$ across the population would reduce the proportion of adolescent drinkers transitioning to binge drinking by $6 \%(\mathrm{AAF}=-0.06$ $(95 \% \mathrm{CI}=-0.08$ to -0.03$))$ and eliminating the exposure entirely would reduce it by $20 \%(\mathrm{AAF}=-0.20(95 \%$ $\mathrm{CI}=-0.28$ to -0.13$)$ ).

\section{Contrasts: time to onset versus time to progression}

to binge drinking

Several variables predicted both alcohol onset and progression to binge drinking-peer alcohol use, age, MAE, receptivity to alcohol marketing, and rebelliousness. In contrast, some variables played a role in alcohol onset but not binge drinking or vice versa. Notably, none of the family predictors of alcohol onset were significant predictors of progression to binge drinking. For unskilled parenting and sensation seeking, the HR was 
Table 4 Crude and adjusted hazard ratios for time to onset of binge drinking

\begin{tabular}{|c|c|c|}
\hline \multirow[b]{2}{*}{ Predictor variable } & \multicolumn{2}{|l|}{ HR progression } \\
\hline & Crude & Adjusted \\
\hline \multicolumn{3}{|l|}{ Sociodemographics } \\
\hline Oldest versus youngest & 3.48 (2.58 to 4.71$)$ & $1.80(1.26$ to 2.56$)$ \\
\hline African-American versus Caucasian & $0.37(0.26$ to 0.55$)$ & $0.42(0.28$ to 0.62$)$ \\
\hline Hispanic versus Caucasian & $0.37(0.59$ to 0.91$)$ & 0.69 (0.55 to 0.88$)$ \\
\hline Other non-Caucasian versus Caucasian & $0.81(0.60$ to 1.10$)$ & 0.68 (0.51 to 0.92$)$ \\
\hline Female & 0.95 (0.81 to 1.10$)$ & $0.96(0.82$ to 1.14$)$ \\
\hline High parent education & 1.58 (1.21 to 2.05$)$ & 1.27 (0.90 to 1.79$)$ \\
\hline Low family income & $0.59(0.46$ to 0.75$)$ & $1.01(0.72$ to 1.41$)$ \\
\hline \multicolumn{3}{|l|}{ Family and friends } \\
\hline Parent alcohol use & 1.70 (1.29 to 2.23$)$ & $1.14(0.85$ to 1.54$)$ \\
\hline Alcohol available at home & 1.90 (1.53 to 2.37$)$ & $1.12(0.88$ to 1.43$)$ \\
\hline Unskilled parenting & 2.08 (1.54 to 2.78$)$ & $1.00(0.72$ to 1.39$)$ \\
\hline High peer alcohol use & 4.68 (3.68 to 5.96$)$ & $2.80(2.10$ to 3.74$)$ \\
\hline \multicolumn{3}{|l|}{ Media and marketing } \\
\hline Low TV viewing & $1.32(0.95$ to 1.82$)$ & $1.18(0.84$ to 1.67$)$ \\
\hline High movie alcohol exposure & 2.47 (1.86 to 3.27$)$ & $1.63(1.20$ to 2.21$)$ \\
\hline Views movies without parents & 1.89 (1.41 to 2.50$)$ & $1.33(0.97$ to 1.80$)$ \\
\hline Receptive to alcohol marketing & 1.74 (1.43 to 2.12$)$ & $1.24(1.00$ to 1.54$)$ \\
\hline \multicolumn{3}{|l|}{ Characteristics of adolescent } \\
\hline High sensation seeking & 2.56 (1.92 to 3.43$)$ & $1.23(0.86$ to 1.76$)$ \\
\hline High rebelliousness & 1.90 (1.51 to 2.40$)$ & $1.45(1.07$ to 1.98$)$ \\
\hline Poor school performance & 1.67 (1.25 to 2.22$)$ & $1.21(0.87$ to 1.68$)$ \\
\hline Low extracurricular involvement & 2.04 (1.48 to 2.80$)$ & 1.48 (1.05 to 2.08$)$ \\
\hline High spending money & 1.91 (1.35 to 2.69$)$ & $1.14(0.80$ to 1.62$)$ \\
\hline
\end{tabular}

significantly higher for onset than for binge drinking by factors of 1.76 and 1.69, respectively. Race/ethnicity did not predict onset, however, White adolescents were more likely to transition to binge drinking, with the effects for African-Americans and Hispanics being significantly stronger for binge drinking than onset by factors of 2.38 and 1.42 , respectively.

\section{DISCUSSION}

This study compared movie alcohol and alcohol marketing exposures with family factors and other variables as predictors of alcohol use onset separately from transition to binge drinking. We found that movie and marketing exposures predicted both transitions. After control for multiple covariates, MAE accounted for $28 \%$ of the alcohol onset and $20 \%$ of the binge drinking transitions observed in this cohort, making it a risk factor with important public health implications and arguing for policy approaches to prevention of MAE. These results are consistent with a German study that also found an association of MAE with alcohol onset and binge drinking, ${ }^{14}$ which adds cross-cultural validation to the findings. In contrast, family characteristicsavailability of alcohol at home, parental drinking, and parenting practices-predicted alcohol onset but not the transition to binge drinking.

We think the results could reflect two types of processes. For onset, drinking is a proscribed behaviour for adolescents and initiating requires that a youth go against cultural and legal norms. Adolescents who are older and who seek new sensations and experiences are less influenced by these norms hence are more likely to try alcohol. However, parents can communicate norms about alcohol use, and the likelihood of onset is reduced when parents have a warm relationship with children, monitor their behaviour and make alcohol unavailable in the home. Once a youth has tried alcohol, progression to problem drinking probably depends on a substance-using peer environment, a lower level of attachment to conventional social institutions, greater involvement in drinking culture (determined in part by marketing and entertainment media) and the belief that alcohol has positive effects in several areas. ${ }^{38}$ Peers may facilitate alcohol use initially through encouraging trial and subsequently through providing an alternative norm structure that reinforces deviant behaviour; adolescents who are more rebellious and less involved in conventional activities should be most susceptible to this kind of influence.

Movie alcohol exposure and alcohol marketing may contribute to both of these processes though for somewhat different reasons. Movie exposure may facilitate onset through providing examples of persons drinking and promoting the belief that alcohol use is common and acceptable. The effect of movie exposure on progression, we suggest, derives from the fact that alcohol use in movies is typically modelled in positive situations, without negative effects, and often shown with 
alcohol brands, ${ }^{9}$ which consolidates both the adolescent's identity as a drinker and brand allegiance. Acquisition of alcohol-branded merchandise, an article of clothing with an alcohol brand on it, furthers this process. Moreover, wearing alcohol-branded merchandise in public engages the adolescent in the actual marketing campaign, as the adolescent is seen by others as an endorsement of use of the brand. We note that in contrast to the present findings for alcohol, one recent study suggests that movie influence on smoking onset is larger than that on progression, ${ }^{39}$ perhaps because for smoking, nicotine addiction drives progression to a greater extent than other types of influences. ${ }^{40}$

\section{Limitations}

Consistent with other contemporary random digit dial household surveys, the response rate for this study was moderate and should be considered for the generalisability of the results, though the sample appeared to be representative with respect to most sociodemographic categories. Also, there was attrition from the panel, and although the multiple imputation procedure minimised attrition bias, attrition reduces power, and this should be recognised as a limit to the ability to generalise to minority groups more likely to drop out of the study. As with any observational study, the possibility of an unmeasured confounder needs to be considered. The covariate for television viewing may not have adequately captured exposure to alcohol depictions in television programming ${ }^{4142}$ and the one for alcohol marketing did not capture television or internet alcohol advertising exposures. ${ }^{43}$ Finally, further research should be conducted to determine how media exposures are related to alcohol use in late adolescence and emerging adulthood.

\section{Implications for parents, families and clinicians}

The findings raise the question about what parents could do to limit MAE and alcohol marketing exposures. One approach to limiting MAE could be through parental restriction on certain types of media, for example, R-rated movies, which contain high levels of drinking $(90 \%)$ and brand placement $(61 \%) .{ }^{9}$ Indeed, parental movie restrictions have been associated with lower risk for alcohol and tobacco use, ${ }^{44-46}$ and parental media management merits greater emphasis by clinicians and intervention researchers. Additionally, this and other research strongly indicates that parents should not allow alcohol-branded merchandise in their homes ${ }^{16} 31$ 47-51; this type of alcohol marketing seems particularly problematic because adolescents become promotional vehicles as they wear their merchandise in schools and other public places, another point clinicians can make when discussing substance use prevention in office visits. The study also suggests that parents may limit onset of alcohol use by being responsive and setting limits, by promoting extracurricular involvement, by keeping home alcohol in a secure location or by not drinking frequently themselves.

\section{Public health considerations}

Product placement in movies is forbidden for cigarettes in the USA but is legal and commonplace for the alcohol industry, with half of Hollywood films containing at least one alcohol brand appearance, regardless of film rating. ${ }^{9}$ To the extent that alcohol product placement serves to increase prevalence of movie drinking scenes, limits on movie alcohol product placement could also reduce MAE. Moreover, movie smoking has declined since it became a public health issue and movie studios began monitoring its prevalence ${ }^{52}$; MAE may deserve similar emphasis.

Finally, the global health implications of risk behaviour depiction in Hollywood movies should be mentioned. For some 20 years now, more than half of the revenues for Hollywood movies come from overseas. ${ }^{53}$ The main importers of Hollywood products are European countries, but Japan and Canada, Australia, Brazil and South Korea are also important markets. The fact that adolescents who view these movies may also be influenced though visual images from movie exports is underlined by the German studies mentioned above. ${ }^{15} 54$ Like influenza, images in Hollywood movies begin in one region of the world then spread globally, where they may affect drinking behaviours among adolescents everywhere they are distributed.

Funding The study was funded by the National Institutes of Health (AA015591 and CA077026, JDS principal investigator, and CA071789 and DA021856,

TAW principal investigator).

\section{Competing interests None.}

Contributors All authors contributed to the conception and design of the study and were part of the development of the surveys deployed in the study. MS conducted the data analysis. All authors had a hand in the interpretation of the data, the critical revision of the manuscript and all approved of the final version.

Provenance and peer review Not commissioned; externally peer reviewed.

Data sharing statement Statistical code and a partial analysis data set (with variables pertaining to this manuscript) are available from the corresponding author. Informed consent was not obtained for data sharing, but the data that would be shared have no personal identifiers. Requests for use of the aforementioned data will not be granted without approval by the Dartmouth and the recipient's human subjects committees.

\section{REFERENCES}

1. Johnston LD, O'Malley PM, Bachman JG, et al. Monitoring the Future national results on adolescent drug use: Overview of key findings, 2010. Ann Arbor: Institute for Social Research, The University of Michigan, 2011:77.

2. Windle M. Alcohol Use Among Adolescents. Thousand Oaks: Sage, 1999.

3. Fergusson DM, Lynskey MT. Alcohol misuse and adolescent sexual behaviors and risk taking. Pediatrics 1996;98:91-6.

4. Pedersen W, Skrondal A. Alcohol and sexual victimization: a longitudinal study of Norwegian girls. Addiction 1996;91:565-81.

5. Ellickson PL, Tucker JS, Klein DJ. Ten-year prospective study of public health problems associated with early drinking. Pediatrics 2003;111:949-55

6. National Highway Traffic Safety Administration (NHTSA). Traffic Safety Facts: Alcohol. Traffic Safety Facts: Crash Stats. Washington DC: U.S. Department of Transportation, 2006.

7. Grant BF, Dawson DA. Age at onset of alcohol use and its association with DSM-IV alcohol abuse and dependence: results from the National Longitudinal Alcohol Epidemiologic Survey. J Subst Abuse 1997;9:103-10. 
8. Hawkins JD, Graham JW, Maguin E, et al. Exploring the effects of age of alcohol use initiation and psychosocial risk factors on subsequent alcohol misuse. J Stud Alcohol 1997;58:280-90.

9. Dal Cin S, Worth KA, Dalton MA, et al. Youth exposure to alcohol use and brand appearances in Popular contemporary movies. Addiction 2008;103:1925-32.

10. Everett SA, Schnuth RL, Tribble JL. Tobacco and alcohol use in top-grossing American films. J Community Health 1998;23:317-24.

11. Roberts D, Henriksen L, Christenson P. Substance Use in Popular Movies and Music. Rockville, MD: Office of National Drug Control Policy and Department of Health and Human Services Substance Abuse and Mental Health Services Administration, 1999. Report No.: ISBN 0-16-050020-6.

12. Sargent JD, Wills TA, Stoolmiller M, et al. Alcohol use in motion pictures and its relation with early-onset teen drinking. J Stud Alcohol 2006;67:54-65

13. Stern SR. Messages from teens on the big screen: smoking, drinking, and drug use in teen-centered films. J Health Commun 2005; 10:331-46

14. Hanewinkel R, Sargent JD. Longitudinal study of exposure to entertainment media and alcohol use among german adolescents. Pediatrics 2009;123:989-95.

15. Hanewinkel R, Tanski SE, Sargent JD. Exposure to alcohol use in motion pictures and teen drinking in Germany. Int $J$ Epidemiol 2007;36:1068-77.

16. McClure AC, Dal Cin S, Gibson J, et al. Ownership of alcoholbranded merchandise and initiation of teen drinking. Am J Prev Med 2006;30:277-83

17. Hastings G, Anderson S, Cooke E, et al. Alcohol marketing and young people's drinking: a review of the research. $J$ Public Health Policy 2005:26:296-311.

18. Dal Cin S, Worth KA, Gerrard M, et al. Watching and drinking: expectancies, prototypes, and friends' alcohol use mediate the effect of exposure to alcohol use in movies on adolescent drinking. Health Psychol 2009;28:473-83.

19. Wills TA, Sargent JD, Gibbons FX, et al. Movie exposure to alcoho cues and adolescent alcohol problems: A longitudinal analysis in a national sample. Psychol Addict Behav 2009;23:23-35.

20. Gibbons FX, Pomery EA, Gerrard M, et al. Media as social influence: racial differences in the effects of peers and media on adolescent alcohol cognitions and consumption. Psychol Addict Behav 2011:24:649-59.

21. Wills TA, Sandy JM, Yaeger AM. Moderators of the relation between substance use level and problems: test of a self-regulation model in middle adolescence. J Abnorm Psychol 2002;111:3-21.

22. Flay BR, Hu FB, Siddiqui O, et al. Differential influence of parental smoking and friends' smoking on adolescent initiation and escalation of smoking. J Health Soc Behav 1994;35:248-65.

23. Steinberg L, Fletcher A, Darling N. Parental monitoring and peer influences on adolescent substance use. Pediatrics 1994;93:1060-4

24. Mares SHW, van der Vorst $\mathrm{H}$, Engels RCME, et al. Parental alcohol use, alcohol-related problems, and alcohol-specific attitudes, alcoholspecific communication, and adolescent excessive alcohol use and alcohol-related problems: An indirect path model. Addict Behav 2011:36:209-16.

25. The American Association for Public Opinion Research. Standard Definitions:Final Dispositions of Case Codes and Outcome Rates for Surveys. 3rd edn. Lenexa, Kansas: AAPOR, 2004.

26. Brick JM, Waksberg J, Kulp D, et al. Bias in list-assisted telephone samples. Public Opin Q 1995;59:218-35.

27. Schafer JL, Graham JW. Missing data: our view of the state of the art. Psychol Methods 2002;7:147-77.

28. Graham JW. Missing data analysis: making it work in the real world. Annu Rev Psychol 2009;60:549-76.

29. Sargent JD, Worth KA, Beach M, et al. Population-based assessment of exposure to risk behaviors in motion pictures. Commun Methods Meas 2008;2:1-18.

30. Pierce JP, Choi WS, Gilpin EA, et al. Tobacco industry promotion of cigarettes and adolescent smoking. JAMA 1998;279:511-15.
31. McClure AC, Stoolmiller M, Tanski SE, et al. Alcohol-branded merchandise and its association with drinking attitudes and outcomes in US adolescents. Arch Pediatr Adolesc Med 2009;163:211-17.

32. Jackson C, Bee-Gates DJ, Henriksen L. Authoritative parenting, child competencies, and initiation of cigarette smoking. Health Educ $Q$ 1994;21:103-16.

33. Sargent JD, Tanski S, Stoolmiller M, et al. Using sensation seeking to target adolescents for substance use interventions. Addiction 2010;105:506-14.

34. Sargent JD, Beach ML, Dalton MA, et al. Effect of seeing tobacco use in films on trying smoking among adolescents: cross sectional study. BMJ 2001;323:1394-7.

35. R Development Core Team. R: a Language and Environment for Statistical Computing. Vienna: R Foundation for Statistical Computing, 2010.

36. van Buuren S, Groothuis-Oudshoorn K. MICE: Multivariate imputation by chained equations in R. Journal of Statistical Software. In Press.

37. Allison PD. Event History analysis: regression for longitudinal event data. In: Su, ed. Quantative Applications in the Social Sciences, Vol 46. Thousand Oaks, CA: Sage Publications, Inc, 1984:46.

38. Wills TA, Sandy JM, Yaeger AM. Stress and smoking in adolescence: a test of directional hypotheses. Health Psychol 2002;21:122-30.

39. Dal Cin S, Stoolmiller M, Sargent JD. When movies matter: exposure to smoking in movies and changes in smoking behavior. $J$ Health Commun. Published Online First: 15 November 2011. doi:10.1080/ 10810730.2011 .585697$.

40. DiFranza JR, Savageau JA, Fletcher K, et al. Symptoms of tobacco dependence after brief intermittent use: the Development and Assessment of Nicotine Dependence in Youth-2 study. Arch Pediatr Adolesc Med 2007;161:704-10.

41. Breed W, De Foe JR. Drinking and smoking on television, 1950-1982. J Public Health Policy 1984;5:257-70.

42. Christenson PG, Henriksen L, Roberts DF. Substance Use in Popular Prime-Time Television. Washington, DC: Office of National Drug Control Policy, Mediascope Macro International, Inc, 2000.

43. Center on Alcohol Marketing and Youth. Youth Exposure to Alcohol Ads on Television, 2002: From 2001 to 2002, Alcohol's Adland Grew Vaster. Washington, DC: Georgetown University, 2004

44. Dalton MA, Ahrens MB, Sargent JD, et al. Relation between parental restrictions on movies and adolescent use of tobacco and alcohol. Eff Clin Pract 2002;5:1-10.

45. Hanewinkel R, Morgenstern M, Tanski SE, et al. Longitudinal study of parental movie restriction on teen smoking and drinking in Germany. Addiction 2008;103:1722-30.

46. Sargent JD, Beach ML, Dalton MA, et al. Effect of parental R-rated movie restriction on adolescent smoking initiation: a prospective study. Pediatrics 2004;114:149-56.

47. Collins RL, Ellickson PL, McCaffrey D, et al. Early adolescent exposure to alcohol advertising and its relationship to underage drinking. J Adolesc Health 2007;40:527-34.

48. Fisher LB, Miles IW, Austin SB, et al. Predictors of initiation of alcoho use among US adolescents: findings from a prospective cohort study. Arch Pediatr Adolesc Med 2007:161:959-66.

49. Henriksen L, Feighery EC, Schleicher NC, et al. Receptivity to alcoho marketing predicts initiation of alcohol use. $J$ Adolesc Health 2008:42:28-35

50. Hurtz SQ, Henriksen L, Wang YUN, et al. The relationship between exposure to alcohol advertising in stores, owning alcohol promotional items, and adolescent alcohol use. Alcohol Alcohol 2007;42:143-9.

51. Workman JE. Alcohol promotional clothing items and alcohol use by underage consumers. Fam Consum Sci Res J 2003;31:331-54.

52. Sargent JD, Heatherton TF. Comparison of trends for adolescent smoking and smoking in movies, 1990-2007. JAMA 2009;301:2211-13.

53. Scott AJ. Hollywood in an Era of Globalization: Opportunities and Predicaments. New Haven: Yale Center for the Study of Globalization; 2002.

54. Hanewinkel R, Sargent JD. Exposure to smoking in internationally distributed American movies and youth smoking in Germany: a crosscultural cohort study. Pediatrics 2008;121:e108-17. 